\title{
Electrical properties of Y-type hexaferrite
}

\author{
Bibhuti B. Sahu*, S. K. Patri* ${ }^{*}$, Banarji Behera ${ }^{\dagger}$ and B. Maharana ${ }^{\dagger}$ \\ *Department of Physics, Veer Surendra Sai University of Technology, Burla, \\ Sambalpur 768018, Odisha, India \\ ${ }^{\dagger}$ Material Research Laboratory, School of Physics, Sambalpur University, \\ Jyoti Vihar, Burla, Sambalpur 768019, Odisha, India

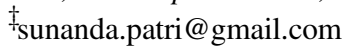

Received 16 January 2018; Revised 7 June 2018; Accepted 10 June 2018; Published 6 July 2018

\begin{abstract}
The polycrystalline sample of $\mathrm{Ba}_{2} \mathrm{Mg}_{2} \mathrm{Fe}_{12} \mathrm{O}_{22}$ was prepared by solid-state reaction technique. Room-temperature X-ray diffraction (XRD) has confirmed the formation of rhombohedral structure. The electrical properties of the sample were studied in wide ranges of temperatures and frequencies. The impedance analysis indicates the presence of bulk effect. The bulk resistance of the material decreases with rise in temperature and exhibits NTCR behavior. This compound also exhibits the temperature-dependent non-Debye type of relaxation phenomena. The presence of non-Debye type of relaxation has been confirmed by the complex impedance analysis. The variation of DC conductivity (bulk) with temperature demonstrates that the compound exhibits Arrhenius type of electrical conductivity. The activation energy of the compound is found to be $0.55 \mathrm{eV}$ in high-temperature region.
\end{abstract}

Keywords: Solid-state reaction; X-ray diffraction; dielectric properties; impedance properties; electrical conductivity.

\section{Introduction}

Hexaferrite materials are characterized by helical magnetic order and ferroelectricity. These days, hexaferrites became important materials for commercial and technological applications, such as in permanent magnets, magnetic recording, data storage media components in electrical devices operating at wireless frequency, $\mathrm{GHz}$ electromagnetic wave absorbers for ECM, RAM and stealth technologies. ${ }^{1}$ According to the chemical composition and crystal structure, hexaferrites are divided into different types such as $\mathrm{M}\left(\mathrm{AFe}_{12} \mathrm{O}_{19}\right)$, $\mathrm{W}\left(\mathrm{AMe}_{2} \mathrm{Fe}_{16} \mathrm{O}_{27}\right), \quad \mathrm{X}\left(\mathrm{A}_{2} \mathrm{Me}_{2} \mathrm{Fe}_{28} \mathrm{O}_{46}\right), \quad \mathrm{Y}\left(A_{2} \mathrm{Me}_{2} \mathrm{Fe}_{12} \mathrm{O}_{22}\right)$, $\mathrm{Z}\left(\mathrm{A}_{3} \mathrm{Me}_{2} \mathrm{Fe}_{24} \mathrm{O}_{41}\right)$ and $\mathrm{U}\left(\mathrm{A}_{4} \mathrm{Me}_{2} \mathrm{Fe}_{36} \mathrm{O}_{60}\right)$, respectively, where $A$ may be $\mathrm{Ba}, \mathrm{Sr}, \mathrm{Pb}, \mathrm{Ca}$, $\mathrm{La}$, etc. and $\mathrm{Me}$ is a bivalent transition metal ion. Among these, the Y-type hexaferrites have gained much interest in recent years due to their application in electronic communication, microwave device and components. $^{2-7}$ The dielectric and conductivity properties of Y-type hexaferrites depend on the preparation method, ion distribution and doping elements. ${ }^{8}$ In fact, the polycrystalline Y-type hexaferrites show high dielectric constants, low AC conductivity and low dielectric losses which make them very useful for microwave applications and chip components. ${ }^{9-12}$ Different groups of researchers have studied the magnetic behavior and the complex permittivity of $\mathrm{Ba}_{2} \mathrm{Mg}_{2} \mathrm{Fe}_{12} \mathrm{O}_{22}$ (BMFO) in different temperature ranges (10-300 K) to determine the dynamic parameters of phonons and magnetic subsystems in the terahertz and infrared frequencies. ${ }^{13,14}$ Though a lot of work has been done on hexaferrite compounds, not much works have been reported so far on other domains like the dielectric, impedance and modulus properties. Realizing the importance of the Y-type hexaferrites, structural, dielectric and impedance properties of $\mathrm{Ba}_{2} \mathrm{Mg}_{2} \mathrm{Fe}_{12} \mathrm{O}_{22}$ have been reported in this paper. Further, conduction mechanism of the material is being analyzed for possible device applications.

\section{Experimental}

\subsection{Material preparation}

The polycrystalline sample of $\mathrm{Ba}_{2} \mathrm{Mg}_{2} \mathrm{Fe}_{12} \mathrm{O}_{22}$ was synthesized by solid-state reaction method using high-purity $\mathrm{BaCO}_{3}$ (99\%; Merck Specialities Pvt. Ltd., India), $\mathrm{MgO}(\geq 97 \%$; Merck Specialities Pvt. Ltd.) and $\mathrm{Fe}_{2} \mathrm{O}_{3}$ (98\%; Merck Specialities Pvt. Ltd.) in a suitable stoichiometry. These precursors were thoroughly mixed with an agate mortar for $2 \mathrm{~h}$ and then in methanol for another $2 \mathrm{~h}$ to obtain a homogeneous mixture. The mixture was calcined at a temperature of $1050^{\circ} \mathrm{C}$ for $5 \mathrm{~h}$ in air atmosphere in an alumina crucible. The calcined powder was then mixed with polyvinyl alcohol (PVA) and pressed into cylindrical pellets of $12 \mathrm{~mm}$ diameter and $1-2 \mathrm{~mm}$ thickness at a pressure of $3.5 \times 10^{6} \mathrm{~N} / \mathrm{m}^{2}$ by using a hydraulic press. The obtained pellets were then sintered at a temperature $1050^{\circ} \mathrm{C}$ for $40 \mathrm{~min}$ in a microwave furnace in air atmosphere. The sintered pellets were polished by fine emery paper to make both surfaces flat and parallel and coated with high-purity silver paste and dried at $150^{\circ} \mathrm{C}$

This is an Open Access article published by World Scientific Publishing Company. It is distributed under the terms of the Creative Commons Attribution 4.0 (CC-BY) License. Further distribution of this work is permitted, provided the original work is properly cited. 
for $2 \mathrm{~h}$ to remove moisture and cooled to room temperature before taking any electrical measurement.

\subsection{Material characterization}

The compound formation and basic structural data were studied by an X-ray diffraction (XRD) technique at room temperature with a powder diffractometer (RIGAKU Ultima IV) using $\mathrm{Cu}-\mathrm{K}_{\alpha}$ radiation $(\lambda=1.5405 \AA)$ in a wide range of Bragg angles $2 \theta\left(20^{\circ} \leq 2 \theta \leq 80^{\circ}\right)$ at a scanning rate of $3^{\circ}$ min. The surface morphology of the compound was studied using scanning electron microscope (SEM; model: SU3500, HITACHI). The electrical property of the compound was measured by using a computer-controlled impedance analyzer (model: IM3532, HIOKI) as a function of frequency $(100 \mathrm{~Hz}-1 \mathrm{MHz})$ in the temperature range between $25^{\circ} \mathrm{C}$ and $450^{\circ} \mathrm{C}$.

\section{Result and Discussion}

\subsection{Structural and microstructural studies}

Figure 1(a) shows the X-ray diffraction pattern of BMFO. The diffraction peaks of the compound were indexed in different crystal systems and unit cell configuration using a standard computer program package "POWD" and were compared with similar compounds of JCPDS file. ${ }^{15}$ The peaks observed in the XRD pattern compared well with the peak positions of Y-phase, ${ }^{16} \mathrm{BaFe}_{2} \mathrm{O}_{4}, \mathrm{MgFe}_{2} \mathrm{O}_{4}$ and $\mathrm{BaFe}_{12} \mathrm{O}_{19}$ (JCPDS file nos. 772337, 702468, 011114 and 840757) as indicated in the figure. A rhombohedral unit cell was selected on the basis of good agreement between the observed and calculated interplanar spacings $d$ (i.e., $\Delta d=d_{\mathrm{obs}}-d_{\mathrm{cal}}=$ minimum). The lattice parameters are $a=b=5.8668 \AA, c=43.4962 \AA$ and $V=1296.56 \AA^{3}$.
The XRD pattern and the unit cell parameters are in good agreement with those reported earlier. ${ }^{16,17}$ Using refined lattice parameters, each peak was indexed and interplanar spacing $d$ of the reflection planes of the compound was calculated and compared with its observed value (Table 1). Figure 1(b) shows the SEM micrograph of calcined powder recorded at room temperature. It was observed that the hexagonal plate-like grains are distributed uniformly over the entire surface of the sample. The distribution of grains and shape in the microstructure exhibit the polycrystalline nature of the sample.

\subsection{Dielectric study}

Figure 2(a) and its inset show the variations of dielectric constant $\left(\varepsilon_{r}\right)$ and loss tangent $(\tan \delta$ ) of BMFO with temperature at $100 \mathrm{kHz}, 500 \mathrm{kHz}$ and $1 \mathrm{MHz}$, respectively. It has been observed that both $\varepsilon_{r}$ and $\tan \delta$ decrease with increase in frequency, which is a general feature of polar dielectric materials. ${ }^{18}$ The dielectric constant of polar dielectric material is due to the contribution of polarizability at lowfrequency region. The value of dielectric constant increases with increase of temperature to a maximum value $\left(\varepsilon_{\max }\right)$ and gradually decreases. This may occur in correspondence to structural modifications, suggesting that the dielectric constant peaks observed probably indicate a phase transition. ${ }^{19}$ In the high-temperature region, higher value of dielectric constant may be due to the space charge polarization, which comes from mobility of ions and presence of imperfections in the materials. The maximum values of dielectric constant $\left(\varepsilon_{\max }\right)$ at $T_{c}$ for $100 \mathrm{kHz}, 500 \mathrm{kHz}$ and $1 \mathrm{MHz}$ are 1485.43 , 826.68 and 738.44 , respectively. The trend of variation is similar for $\tan \delta$ versus temperature response. The anomaly in $\tan \delta$ plot may be attributed to the dielectric relaxation in the material.

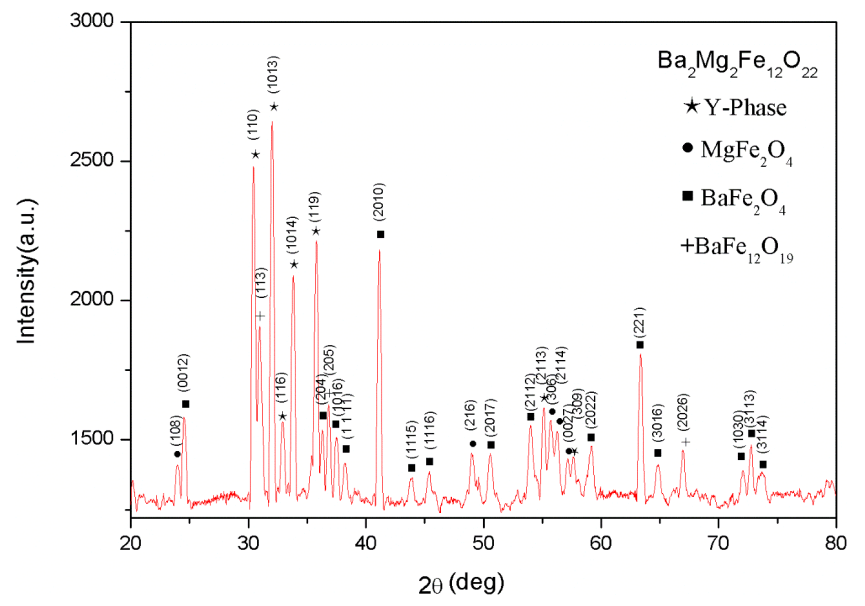

(a)

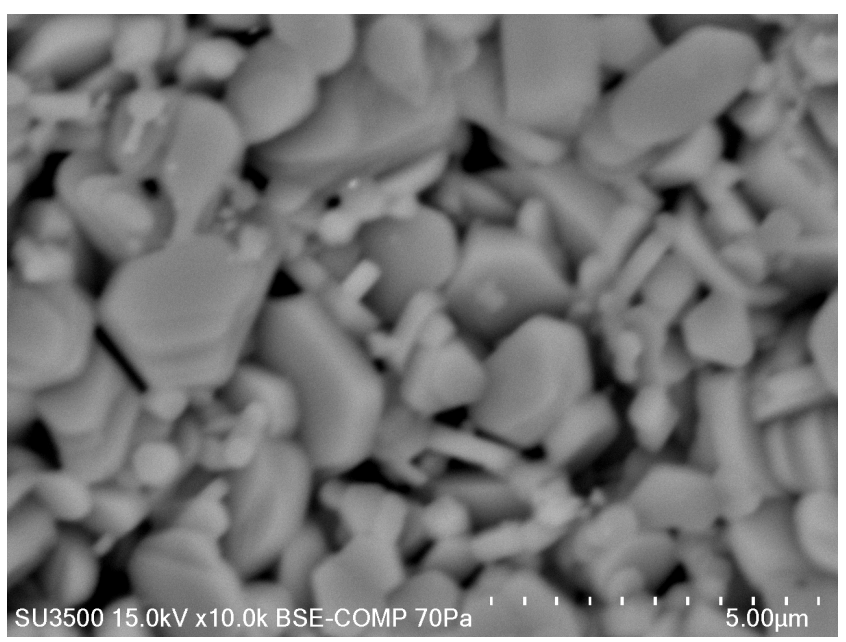

(b)

Fig. 1. (a) Room-temperature XRD patterns of $\mathrm{Ba}_{2} \mathrm{Mg}_{2} \mathrm{Fe}_{12} \mathrm{O}_{22}$. (b) $\mathrm{SEM}$ micrograph of $\mathrm{Ba}_{2} \mathrm{Mg}_{2} \mathrm{Fe}_{12} \mathrm{O}_{22}$. 
Table 1. Room-temperature XRD data of $\mathrm{Ba}_{2} \mathrm{Mg}_{2} \mathrm{Fe}_{12} \mathrm{O}_{22}$

\begin{tabular}{|c|c|c|c|c|c|c|}
\hline \multirow[b]{2}{*}{ S. no. } & \multirow[b]{2}{*}{$2 \theta(\mathrm{deg})$} & \multicolumn{2}{|c|}{$d$-spacing $(\AA)$} & \multicolumn{3}{|c|}{ Indices } \\
\hline & & $d$-observed & $d$-calculated & $h$ & $k$ & $l$ \\
\hline 1 & 23.96 & 3.7108 & 3.7123 & 1 & 0 & 8 \\
\hline 2 & 24.50 & 3.6302 & 3.6247 & 0 & 0 & 12 \\
\hline 3 & 30.44 & 2.9340 & 2.9335 & 1 & 1 & 0 \\
\hline 4 & 30.96 & 2.8859 & 2.8753 & 1 & 1 & 3 \\
\hline 5 & 32.02 & 2.7928 & 2.7944 & 1 & 0 & 13 \\
\hline 6 & 32.88 & 2.7216 & 2.7192 & 1 & 1 & 6 \\
\hline 7 & 33.82 & 2.6496 & 2.6506 & 1 & 0 & 14 \\
\hline 8 & 35.78 & 2.5074 & 2.5077 & 1 & 1 & 9 \\
\hline 9 & 36.28 & 2.4740 & 2.4739 & 2 & 0 & 4 \\
\hline 10 & 36.82 & 2.4389 & 2.4387 & 2 & 0 & 5 \\
\hline 11 & 37.50 & 2.3963 & 2.3970 & 1 & 0 & 16 \\
\hline 12 & 38.2 & 2.3540 & 2.3560 & 1 & 1 & 11 \\
\hline 13 & 41.14 & 2.1923 & 2.1937 & 2 & 0 & 10 \\
\hline 14 & 43.94 & 2.0588 & 2.0623 & 1 & 1 & 15 \\
\hline 15 & 45.42 & 1.9951 & 1.9940 & 1 & 1 & 16 \\
\hline 16 & 49 & 1.8574 & 1.8564 & 2 & 1 & 6 \\
\hline 17 & 50.58 & 1.8030 & 1.8028 & 2 & 1 & 17 \\
\hline 18 & 54 & 1.6966 & 1.7970 & 2 & 1 & 12 \\
\hline 19 & 55.10 & 1.6653 & 1.6656 & 2 & 1 & 13 \\
\hline 20 & 55.74 & 1.6477 & 1.6483 & 3 & 0 & 6 \\
\hline 21 & 56.26 & 1.6337 & 1.6336 & 2 & 1 & 14 \\
\hline 22 & 57.18 & 1.6096 & 1.6110 & 0 & 0 & 27 \\
\hline 23 & 57.66 & 1.5973 & 1.5984 & 3 & 0 & 9 \\
\hline 24 & 59.2 & 1.5594 & 1.5603 & 2 & 0 & 22 \\
\hline 25 & 63.38 & 1.4662 & 1.4659 & 2 & 2 & 1 \\
\hline 26 & 64.84 & 1.4367 & 1.4375 & 3 & 0 & 16 \\
\hline 27 & 66.94 & 1.3967 & 1.3972 & 2 & 0 & 26 \\
\hline 28 & 67.02 & 1.3952 & 1.3948 & 1 & 0 & 30 \\
\hline 29 & 72.75 & 1.2988 & 1.2987 & 3 & 1 & 13 \\
\hline 30 & 73.7 & 1.2844 & 1.2838 & 3 & 1 & 14 \\
\hline
\end{tabular}

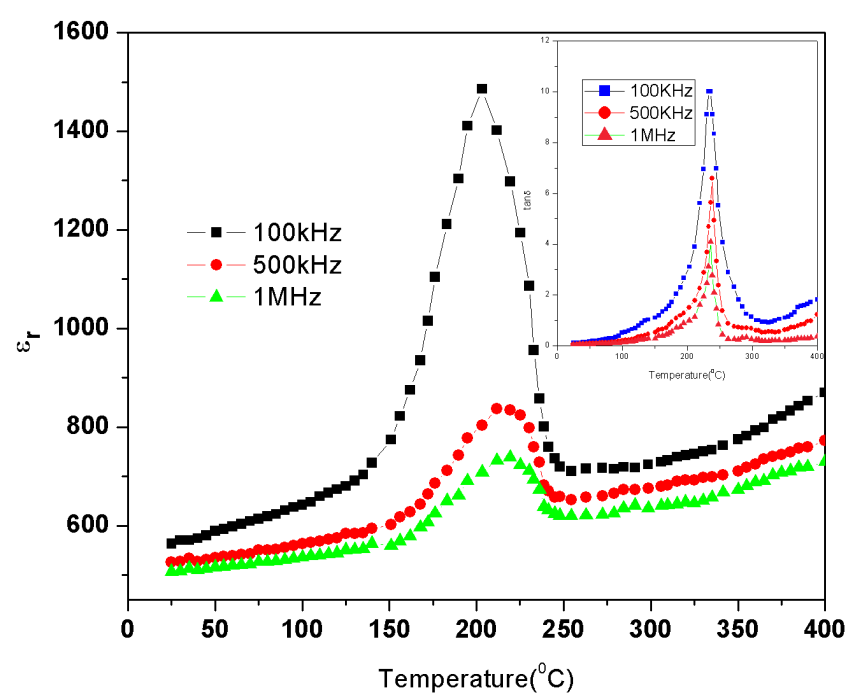

(a)

\subsection{Complex impedance analysis}

The complex impedance spectroscopy (CIS $)^{20}$ is a powerful, most reliable and unique technique for the characterization of electrical response of materials. In the CIS technique, the AC response is analyzed by the application of a sinusoidal perturbation and subsequently the impedance and other related parameters are calculated as a function of perturbation frequency at different temperatures. ${ }^{21-24}$ The capacitive and resistive components of the polycrystalline sample are represented in the Nyquist plot, resulting in succession of semicircle(s). The electrical properties of a material are often represented in terms of complex dielectric constant $\varepsilon^{*}$, complex impedance $Z^{*}$, electrical modulus $M^{*}$ and the loss tangent $(\tan \delta)$. These are correlated to each other as follows:

$$
\begin{aligned}
& \varepsilon^{*}=\varepsilon^{\prime}-j \varepsilon, \\
& Z^{*}=Z^{\prime}-j Z^{\prime \prime}=R-\frac{1}{\omega C}, \\
& M^{*}=M^{\prime}+j M^{\prime \prime}=\frac{1}{\varepsilon^{*}}=j \omega C_{0} Z, \\
& Y^{*}=Y^{\prime}+j Y^{\prime \prime}=\frac{1}{R+\varphi \omega X}, \\
& \tan \delta=\frac{\varepsilon^{\prime \prime}}{\varepsilon^{\prime}}=\frac{M^{\prime \prime}}{M^{\prime}}=\frac{Z^{\prime}}{Z^{\prime \prime}}=\frac{Y^{\prime}}{Y^{\prime \prime}},
\end{aligned}
$$

where $\left(Z^{\prime}, M^{\prime}, Y^{\prime}, \varepsilon^{\prime}\right)$ and $\left(Z^{\prime \prime}, M^{\prime \prime}, Y^{\prime \prime}, \varepsilon^{\prime \prime}\right)$ are real and imaginary components of impedance, electric modulus, admittance and permittivity, respectively, $\omega=2 \pi f$ is the angular frequency and $\sqrt{-1}$ is the imaginary factor.

Figure 3 shows the frequency dependence of $Z^{\prime}$ at different temperatures $\left(125-450^{\circ} \mathrm{C}\right)$. It is observed that $Z^{\prime}$ decreases with increase in temperature, so resistivity

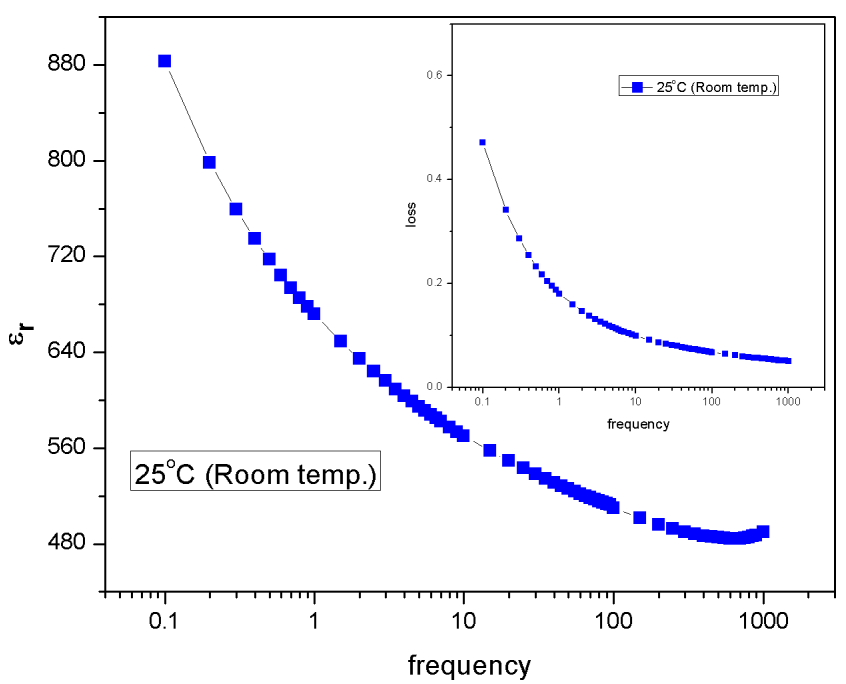

(b)

Fig. 2. Variation of (a) dielectric constant and tangent loss (top right inset) as a function of frequencies, (b) dielectric constant and tangent loss (top right inset) as a function of frequency at room temperature. 


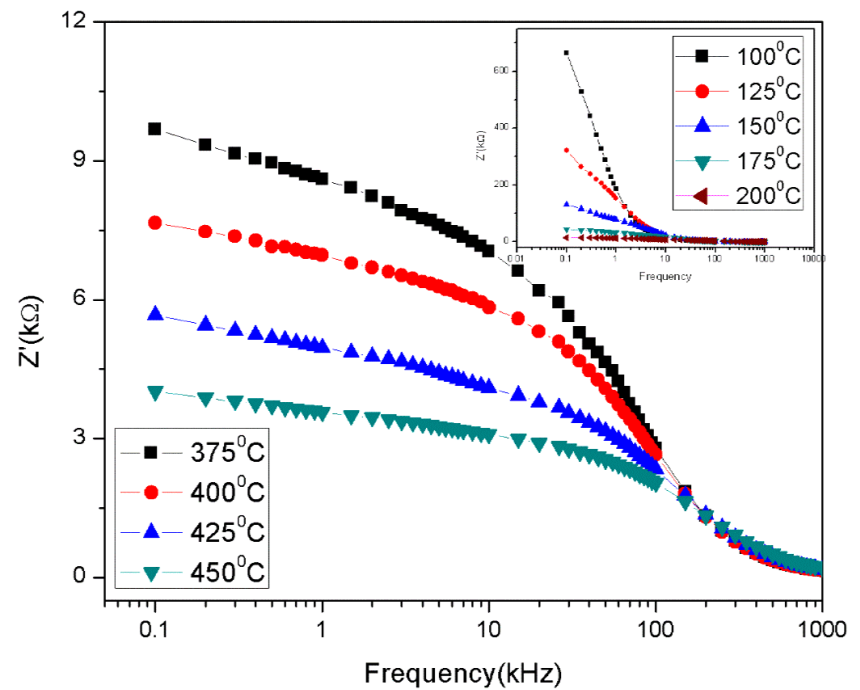

Fig. 3. Variations of $Z^{\prime}$ with frequency at low temperature (inset) and at high temperature.

decreases. It exhibits low-frequency dispersion due to polarization. This shows the increase in conductivity of material with increase in temperature as well as frequency (i.e., negative temperature coefficient of resistance-type (NTCR) behavior as that of semiconductor). Figure 4 shows the frequency dependence of $Z^{\prime \prime}$ at lower and higher temperatures. The magnitude of $Z^{\prime \prime}$ decreases with increase in frequency at high-temperature region. At high temperature the peaks of the plots are shifted towards higher frequency side and it indicates relaxation process in the system. ${ }^{25}$ Figure 5 shows the complex impedance spectra $\left(Z^{\prime}\right.$ versus $\left.Z^{\prime \prime}\right)$ of BMFO at selected temperatures. The appearance of semicircular arcs exhibits that the material shows bulk effect as well as a slight indication of grain boundary effect. As the temperature increases, the intercept point on the real axis shifts

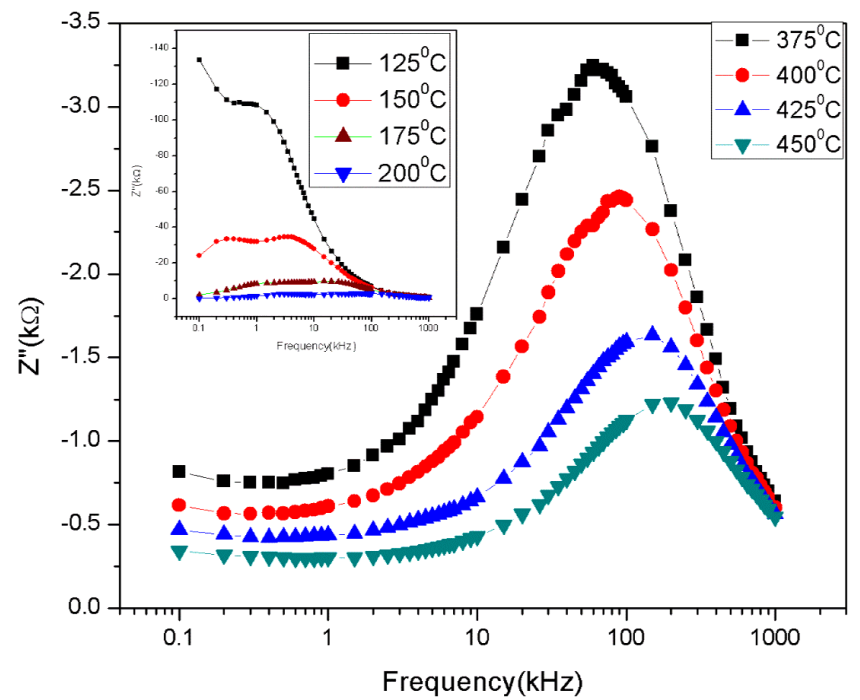

Fig. 4. Variations of $Z^{\prime \prime}$ with frequency at low temperature (inset) and at high temperature.

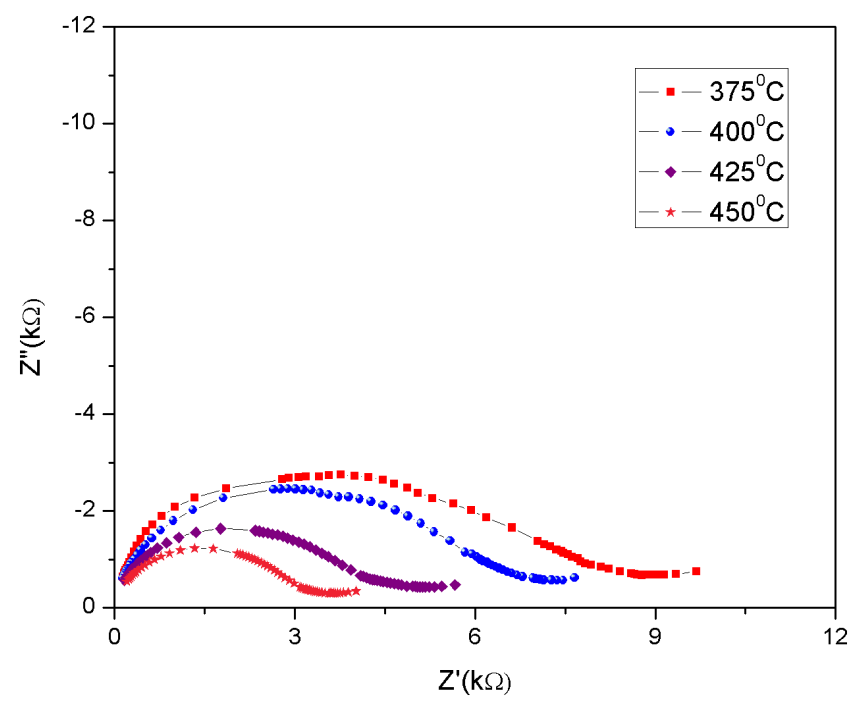

Fig. 5. Nyquist plot of $Z^{\prime}$ versus $Z^{\prime \prime}$ at different temperatures.

toward the origin, which indicates a decrease in resistive properties or bulk resistance of the material. This implies that the sample exhibits negative temperature coefficient of resistance, which is a fundamental characteristic of semiconductor.

\subsection{Complex electric modulus analysis}

The electric modulus is the reciprocal of complex permittivity and was introduced by Macedo $e t$ al. ${ }^{26}$ to study the space charge relaxation process. ${ }^{21}$ The complex electric modulus spectrum represents the measure of ion energies and configuration in the structure. The complex modulus analysis technique is very important for the detection of electrical conductivity, electrode polarization, bulk properties, relaxation time and grain boundary conduction effect. ${ }^{27}$ Complex modulus plot of $M^{\prime \prime}$ versus $M^{\prime}$ is useful in determining the smallest capacitance. ${ }^{28,29}$ The modulus formalism is adopted as it suppresses the polarization effects at the electrode or electrolyte interface. Thus the complex electric modulus spectra reflect the dynamic properties of the sample alone. The electrical response can be analyzed by complex electric modulus formalism. The complex electric modulus $\left(M^{*}\right)$ has been calculated from the impedance data using the following relations:

$$
\begin{aligned}
& M^{*}=M^{\prime}+j M^{\prime \prime}=1 / \varepsilon^{*}=j \omega \varepsilon_{o} Z^{*}, \\
& M^{\prime}=\omega C_{o} Z^{\prime \prime}, \\
& M^{\prime \prime}=\omega C_{o} Z^{\prime},
\end{aligned}
$$

where $\omega=$ angular frequency $(2 \pi f)$ and $C_{0}=$ geometrical capacitance $=\varepsilon_{0}(A / t)$, where $\varepsilon_{0}=$ permittivity of free space, $A=$ area of the electrode surface and $t=$ thickness.

Figure 6 (inset) shows the variations of $M^{\prime}$ with frequency at some high temperatures. The $M^{\prime}$ values approach zero in low-frequency region and a continuous dispersion on 


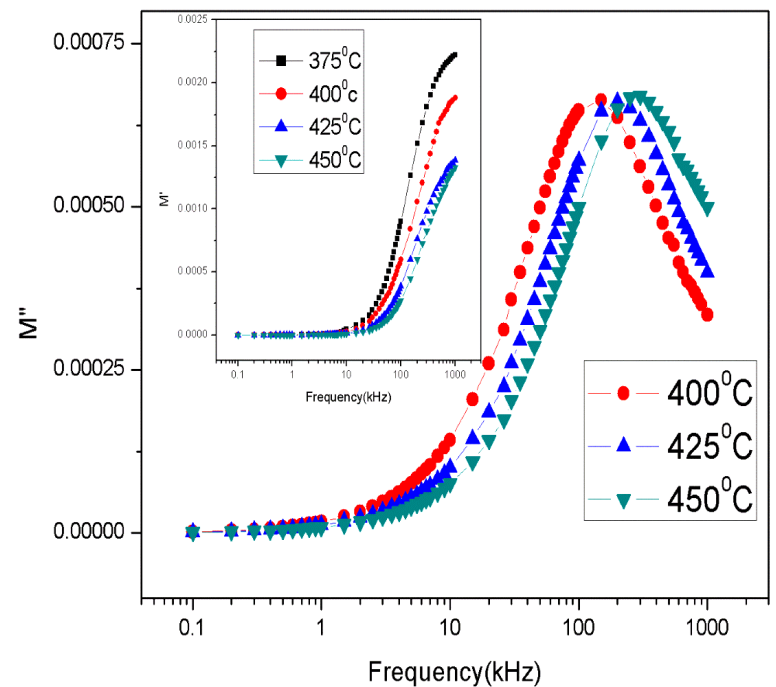

Fig. 6. Variations of $M^{\prime}$ (inset) and $M^{\prime \prime}$ with frequency at different temperatures.

increasing the frequency is observed. This may be contributed due to the conduction of short-range mobility of charge carriers. This implies the lack of restoring force for the flow of charge under the influence of steady electric field. ${ }^{30}$ This confirms the elimination of electrode effect in the material. ${ }^{31}$ Figure 6 shows the variations of imaginary part $\left(M^{\prime \prime}\right)$ of electric modulus with frequency of BMFO at different temperatures. The $M_{\max }^{\prime \prime}$ peaks shift towards the higher frequency side with rise in temperature. This behavior of dielectric relaxation indicates that in thermally activated process, the hopping mechanism of charge carriers dominates intrinsically at higher temperatures. Asymmetric peak broadening indicates the spread of relaxation time with different time constants and hence the relaxation is of non-Debye type. ${ }^{32}$ The complex modulus spectra of BMFO at different temperatures is shown in Fig. 7. The spectra confirms the appearance of asymmetric arcs of semicircle in the complex

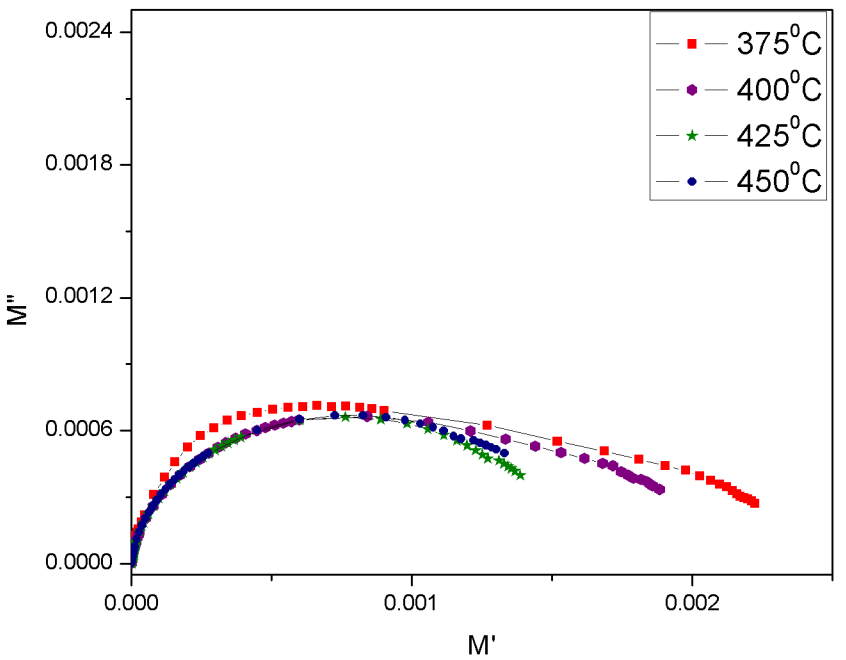

Fig. 7. Variations of $M^{\prime}$ and $M^{\prime \prime}$ at different temperatures. impedance plot which also appear to overlap at all temperatures. This suggests the occurrence of electrical relaxation phenomenon in this material.

\subsection{Conductivity study}

In order to incorporate the effect of conduction mechanism and different types of charge carriers in the material, the electrical conductivity study was performed. The value of AC electrical conductivity $\left(\sigma_{\text {ac }}\right)$ of the material was calculated by using an empirical relation

$$
\sigma_{\mathrm{ac}}=\omega \varepsilon_{r} \varepsilon_{0} \tan \delta
$$

where $\varepsilon_{0}=$ dielectric permittivity of the free space, $\varepsilon_{r}=$ dielectric constant and $\omega$ is the frequency.

Figure 8 shows the variations of AC electrical conductivity with frequency at different temperatures. It has been observed that the spectrum has three different regions, i.e., lower frequency dispersion, higher frequency dispersion and frequency-independent region. $\sigma_{\mathrm{ac}}$ increases with increase in temperature having a high value at higher frequencies. The frequency dependence of electrical conductivity according to the universal power law proposed by Jonscher ${ }^{33}$ and is given by

$$
\sigma_{\mathrm{ac}}=\sigma_{\mathrm{dc}}+A \omega^{n}
$$

where $\sigma_{\mathrm{dc}}$ is the frequency-independent conductivity while the coefficient $A$ and exponent $n$ are material-and temperature-dependent parameters, respectively. The fractional exponent $n$ usually varies between 0 and 1 . The term $A \omega^{n}$ characterizes all dispersion phenomena. At the higher frequency, the conductivity increases due to long-range movement of charge carriers. The intermediate plateau region corresponds to frequency-independent conductivity known as DC conductivity. This region is obtained due to transport of

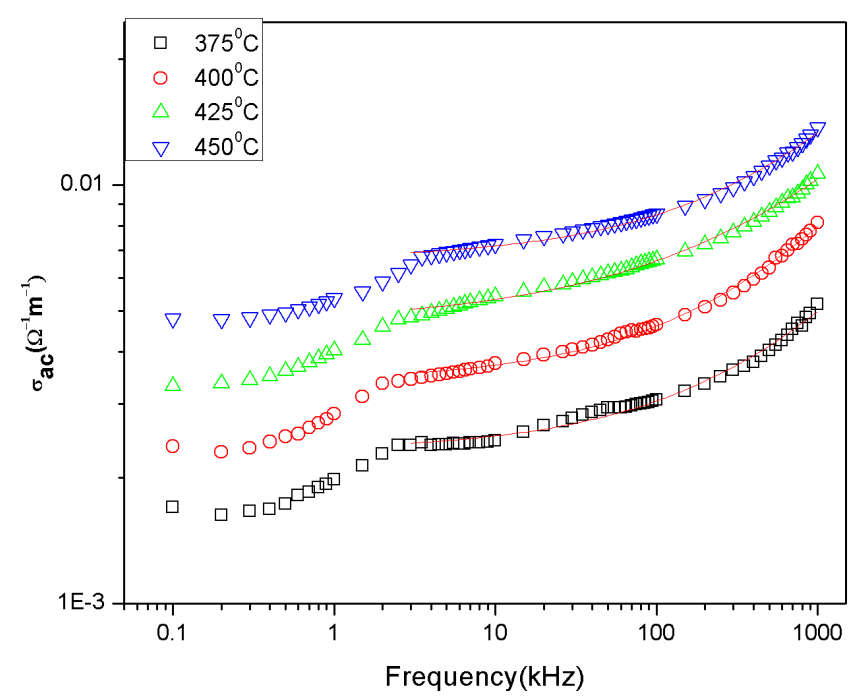

Fig. 8. Variations of $\mathrm{AC}$ conductivities as a function of frequency for various temperatures. 
Table 2. Fitting parameters obtained from Jonscher's power law at different temperatures.

\begin{tabular}{lcccc}
\hline$T\left({ }^{\circ} \mathrm{C}\right)$ & $\sigma_{\mathrm{dc}}\left(\Omega^{-1} \cdot \mathrm{m}^{-1}\right)$ & $A$ & $n$ & Goodness of fit $\left(R^{2}\right)$ \\
\hline 25 (room temperature) & 0.0000064 & $7.813229 \times 10^{-9}$ & 0.87309 & 0.99986 \\
375 & 0.00231 & $1.13741 \times 10^{-6}$ & 0.56205 & 0.99045 \\
400 & 0.0034 & $1.52552 \times 10^{-6}$ & 0.57979 & 0.99647 \\
425 & 0.00469 & $8.3906 \times 10^{-6}$ & 0.47128 & 0.99493 \\
450 & 0.00664 & $2.94848 \times 10^{-6}$ & 0.55989 & 0.99499 \\
\hline
\end{tabular}

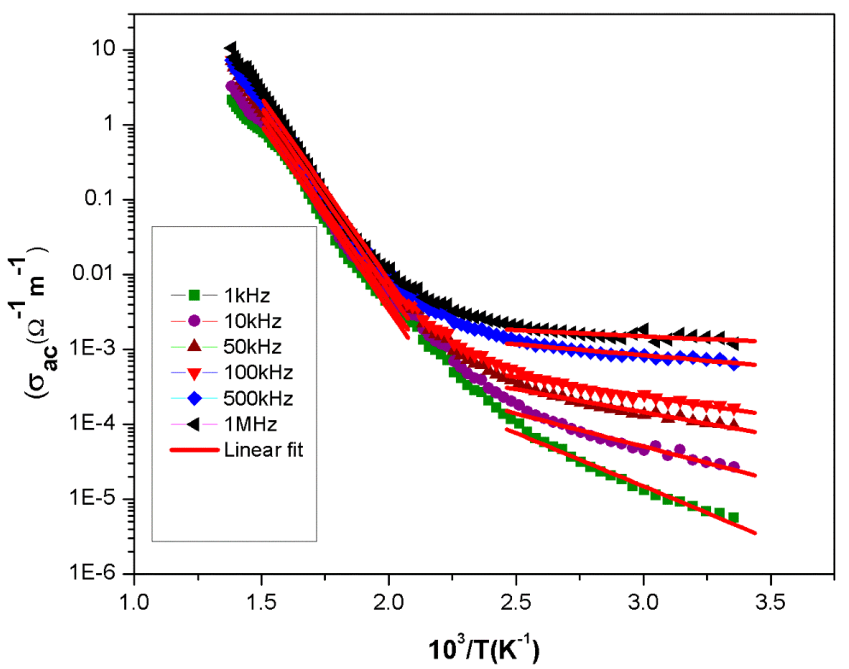

Fig. 9. Variations of $\mathrm{AC}$ conductivity $\left(\sigma_{\mathrm{ac}}\right)$ with the inverse of absolute temperature at different frequencies.

mobile ions in response to applied electric field. ${ }^{34}$ The values of $A, n$ and $\sigma_{\mathrm{dc}}$ are given in Table 2, which are calculated by nonlinear fit of the above equation with experimental data. The solid lines of figure are the fitted lines. The $n$ values for $375^{\circ} \mathrm{C}, 400^{\circ} \mathrm{C}, 425^{\circ} \mathrm{C}$ and $450^{\circ} \mathrm{C}$ are nearly $0.56,0.58,0.47$ and 0.56 , respectively. It clearly indicates that the $n$ value varies between 0 and 1 , which indicates the conduction is thermally activated process.

Figure 9 shows the variations of AC conductivity with the inverse of absolute temperature at various frequencies. The activation energies have been calculated from the slope of linear portion of $\ln \sigma_{\mathrm{ac}}$ versus $10^{3} / \mathrm{T}$ (Fig. 9) and given in Table 3 for the temperature regions of $220-370^{\circ} \mathrm{C}$ and

Table 3. Values of activation energies $(\mathrm{eV})$ of $\mathrm{Ba}_{2} \mathrm{Mg}_{2} \mathrm{Fe}_{12} \mathrm{O}_{22}$ at different frequency and temperature.

\begin{tabular}{lcc}
\hline Frequency $(\mathrm{kHz})$ & $\begin{array}{c}\text { Temperature region 1 } \\
\left(25-120^{\circ} \mathrm{C}\right)\end{array}$ & $\begin{array}{c}\text { Temperature region 2 } \\
\left(220-370^{\circ} \mathrm{C}\right)\end{array}$ \\
\hline 1 & $0.2822 \mathrm{eV}$ & $0.9799 \mathrm{eV}$ \\
10 & $0.1746 \mathrm{eV}$ & $0.9820 \mathrm{eV}$ \\
50 & $0.1205 \mathrm{eV}$ & $0.9669 \mathrm{eV}$ \\
100 & $0.1005 \mathrm{eV}$ & $0.9775 \mathrm{eV}$ \\
500 & $0.0579 \mathrm{eV}$ & $0.96640 \mathrm{eV}$ \\
1000 & $0.0328 \mathrm{eV}$ & $0.96648 \mathrm{eV}$ \\
\hline
\end{tabular}

$25-120^{\circ} \mathrm{C}$. These values suggest that a small amount of energy is required to activate the carriers/electrons for electrical conduction. The decrease in activation energy with increasing frequency suggests that the conduction mechanism in these ceramics may be due to the hopping of charge carriers. At higher frequencies, the activation energy is smaller than that at lower frequencies because of the presence of space-charge polarization in conduction phenomena (at lower frequencies). The activation energy observed in this compound is found to be very small as compared to other hexaferrite structured compound. ${ }^{35}$ There is an indication of substantial enhancement in the AC conductivity with increase in temperature. The conductivities at different frequencies seem to be approaching each other at high-temperature region. These results are in a good agreement with the lowfrequency dispersion and high-frequency plateau obtained at high temperatures.

Figure 10 shows the variation of $\sigma_{\mathrm{dc}}$ with the inverse of absolute temperature $\left(10^{3} / T\right)$. The value of bulk conductivity of the material has been calculated from the impedance plots of the sample at different temperatures. The activation energy is calculated using the Arrhenius equation: $\sigma_{\mathrm{dc}}=\sigma_{0} \exp$ $\left(-E_{a} / K_{B} T\right)$. It is observed that the DC conductivity increases with increase in temperature; hence the material exhibits NTCR behavior like a semiconductor. The activation energy

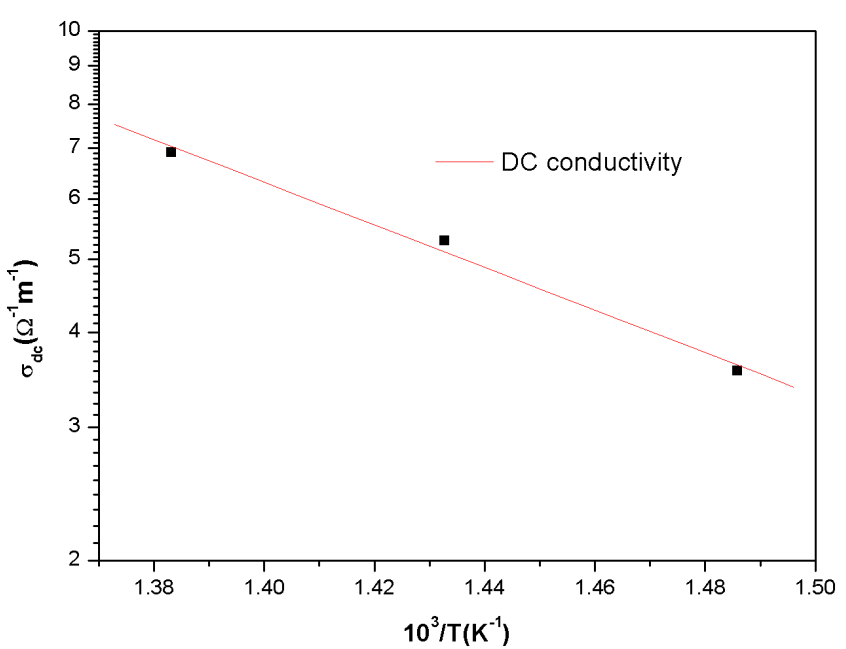

Fig. 10. Variation of DC conductivity $\left(\sigma_{\mathrm{dc}}\right)$ with the inverse of absolute temperature. 
calculated from the slope of the plot in the higher temperature region is found to be $0.55 \mathrm{eV}$. The hopping conduction and dielectric properties may be responsible for low value of activation energy.

\section{Conclusions}

The polycrystalline sample of $\mathrm{Ba}_{2} \mathrm{Mg}_{2} \mathrm{Fe}_{12} \mathrm{O}_{22}$ compound was prepared by a high-temperature $\left(1050^{\circ} \mathrm{C}\right)$ solid-state reaction technique. X-ray analysis exhibits the rhombohedral crystal structure of the compound at room temperature and confirms the crystalline nature of the sample. The maximum values of dielectric constant at $T_{c}$ are found to be 1485.43 , 826.68 and 738.44 at $100 \mathrm{kHz}, 500 \mathrm{kHz}$ and $1 \mathrm{MHz}$ frequencies respectively. The electrical conduction in the compound is due to the bulk effect only. The bulk resistance of the material decreases with rise in temperature and exhibits NTCR behavior. The activation energy of the compound is found to be $0.55 \mathrm{eV}$ in the high-temperature region. The $\mathrm{AC}$ conductivity is found to obey Jonscher's universal power law.

\section{References}

${ }^{1}$ C. P. Robert, Hexagonal ferrites: A review of the synthesis, properties and applications of hexaferrite ceramics, Prog. Mater. Sci. 57, 1191 (2012).

${ }^{2}$ J. C. Anderson, Dielectrics (Chapman \& Hall, London, 1964).

${ }^{3} \mathrm{M}$. Obol and C. Vittoria, Measurement of permeability of oriented Y-type hexaferrites, J. Magn. Magn. Mater. 265, 290 (2003).

${ }^{4}$ F. M. M. Pereira, C. A. R. Junior, M. R. P. Santos, R. S. T. M. Sohn, F. N. A. Freire, J. M. Sasaki, J. A. C. de Paiva and A. S. B. Sombra, Structural and dielectric spectroscopy studies of the M-type barium strontium hexaferrite alloys, J. Mater. Sci. Mater. Electron. 19, 627 (2008).

${ }^{5}$ A. Ghasemi, A. Hossienpour, A. Morisako, A. Saatchi and M. Salehi, Electromagnetic properties and microwave absorbing characteristics of doped barium hexaferrite, J. Magn. Magn. Mater. 302, 429 (2006).

${ }^{6}$ M. J. Iqbal and S. Farooq, Extraordinary role of Ce-Ni elements on the electrical and dielectric properties of Sr-Ba M-type hexaferrite, Mater. Res. Bull. 44, 2050 (2009).

${ }^{7}$ H. Yanbing, S. Jian, S. Lina, T. Quan, L. Qin, J. Hongxiao, J. Dingfeng, B. Hong, G. Hongliang and W. Xinqing, Tailored magnetic properties of $\mathrm{Sm}(\mathrm{Zn})$ substituted nanocrystalline barium hexaferrites, J. Alloys Compd. 486, 348 (2009).

${ }^{8}$ A. Shaikh, S. Bellad and B. Chougule, Temperature and frequency-dependent dielectric properties of $\mathrm{Zn}$ substituted Li-Mg ferrites, J. Magn. Magn. Mater. 195, 384 (1999).

${ }^{9}$ Y. Bai, J. Zhou, Z. Gui and L. Li, Magnetic properties of $\mathrm{Cu}$, Zn-modified $\mathrm{Co}_{2} \mathrm{Y}$ hexaferrites, J. Magn. Magn. Mater. 246, 140 (2002).

${ }^{10}$ M. A. El Hiti and A. M. A. El Ata, Semiconductivity in $\mathrm{Ba}_{2} \mathrm{Ni}_{2-x} \mathrm{Zn}_{x} \mathrm{Fe}_{12} \mathrm{O}_{22}$ Y-type hexaferrite, J. Magn. Magn. Mater. 195, 667 (1999).

${ }^{11}$ J. Smit and H. P. J. Wijn, Ferrites (Philips' Technical Library, Eindhoven, 1959).
${ }^{12}$ H. Kwon, J. Shin and J. H. Oh, The microwave absorbing and resonance phenomena of Y-type hexagonal ferrite microwave absorbers, J. Appl. Phys. 75, 6109 (1994).

${ }^{13}$ I. Shintaro, D. Okuyama, K. Kakurai, M. Nishi, Y. Taguchi and Y. Tokura, Neutron diffraction studies on the multiferroic conical magnet $\mathrm{Ba}_{2} \mathrm{Mg}_{2} \mathrm{Fe}_{12} \mathrm{O}_{22}$, Phys. Rev. B 81, 174418 (2010).

${ }^{14}$ G. A. Komandin, A. S. Prokhorov, V. I. Torgashev, E. S. Zhukova, B. P. Gorshunov and A. A. Bush, Polarization modes in the $\mathrm{Ba}_{2} \mathrm{Mg}_{2} \mathrm{Fe}_{12} \mathrm{O}_{22}$ multiferroic, Phys. Solid State 53, 736 (2011).

${ }^{15} \mathrm{E}$. Wu, POWD: An interactive powder diffraction data interpretation and indexing, J. Appl. Cryst. 22, 506 (1989).

${ }^{16}$ B. J. Rajshree and S. V. Hardev, Y-type hexaferrites: Structural, dielectric and magnetic properties, Solid State Phenom. 189, 209 (2012).

${ }^{17}$ T. Koutzarova, S. Kolev, I. Nedkov, B. Blagoev and C. Ghelev, Magentic properties of nanosized $\mathrm{Ba}_{2} \mathrm{Mg}_{2} \mathrm{Fe}_{12} \mathrm{O}_{22}$ powders obtained by auto-combustion, J. Supercond. Nov. Magn. 25, 2631 (2012).

${ }^{18}$ I. Ertugrul and I. Alime, Dielectric behavior of the catalyst zeolite NaY, Turk. J. Chem. 31, 523 (2007).

${ }^{19}$ H. Khanduri, M. Chandra Dimri, H. Kooskora, I. Heinmaa, G. Viola, H. Ning, M. J. Reece, J. Krustok and R. Stern, Structural, dielectric, magnetic, and nuclear magnetic resonance studies of multiferroic Y-type hexaferrites, J. Appl. Phys. 112, 073903 (2012).

${ }^{20}$ J. R. Macdonald, Impedance Spectroscopy: Emphasizing Solid Materials and Systems (Wiley, New York, 1987).

${ }^{21}$ C. K. Suman, K. Prasad and R. N. P. Choudhary, Complex impedance studies on tungsten-bronze electroceramic: $\mathrm{Pb}_{2} \mathrm{Bi}_{3} \mathrm{LaTi}_{5} \mathrm{O}_{18}$, J. Mater. Sci. 41, 369 (2006).

${ }^{22} \mathrm{~J}$. Suchanicz, The low frequency dielectric relaxation $\mathrm{Na}_{0.5} \mathrm{Bi}_{0.5} \mathrm{TiO}_{3}$ ceramics, Mater. Sci. Eng. B. 55, 114 (1998).

${ }^{23} \mathrm{~S}$. Sen and R. N. P. Choudhary, Impedance studies of $\mathrm{Sr}$ modified $\mathrm{BaZr}_{0.05} \mathrm{Ti}_{0.95} \mathrm{O}_{3}$ ceramics, Mater. Chem. Phys. 87, 256 (2004).

${ }^{24}$ S. Brahma, R. N. P. Choudhary and A. K. Thakur, AC impedance analysis of $\mathrm{LaLiMo}_{2} \mathrm{O}_{8}$ electroceramics, Physica $B$ 355, 188 (2005).

${ }^{25}$ S. K. Satpathy, N. K. Mohanty, A. K. Behera, B. Behera and P. Nayak, Electrical conductivity of $\mathrm{Gd}$ doped $\mathrm{BiFeO}_{3}-\mathrm{PbZrO}_{3}$ composite, Front. Mater. Sci. 7, 295 (2013).

${ }^{26}$ P. B. Macedo, R. Bose, V. Provenzano and T. A. Livitz, Amorphous Materials (Wiley, New York, 1972), p. 251.

${ }^{27}$ I. M. Hodge, M. D. Ingram and A. R. West, A new mwthod for analysing the a.c. behaviour of polycrystalline solid electrolytes, J. Electroanal. Chem. Interfacial Electrochem. 58, 429 (1975).

${ }^{28}$ D. C. Sinclair and A. R. West, Impedance and modulus spectroscopy of semiconducting $\mathrm{BaTiO}_{3}$ showing positive temperature coefficient of resistance, J. Appl. Phys. 66, 3850 (1989).

${ }^{29}$ D. C. Sinclair and A. R. West, Effect of atmosphere on the PTCR properties of $\mathrm{BaTiO}_{3}$ ceramics, J. Mater. Sci. 29, 6061 (1994).

${ }^{30}$ F. Borsa, D. R. Torgeson, S. W. Martin and H. K. Patel, Relaxation and fluctuations in glassy fast-ion conductors: Wide-frequencyrange NMR and conductivity measurements, Phys. Rev. B. 46, 795 (1992).

${ }^{31}$ A. Suresh and G. Sathaiah, Dielectric studies of some Indian granite samples, Int. J. Innov. Res. Sci. Eng. Technol. 3, 11545 (2014). 
${ }^{32}$ J. R. Macdonald, Note on the parameterization of the constantphase admittance element, Solid State Ion. 13, 147 (1984).

${ }^{33}$ A. K. Jonscher, The 'universal' dielectric response, Nature 267, 673 (1977).

${ }^{34}$ T. Badapanda, R. K. Harichandan, S. S. Nayak, A. Mishra and S. Anwar, Frequency and temperature dependence behaviour of impedance, modulus and conductivity of $\mathrm{BaBi}_{4} \mathrm{Ti}_{4} \mathrm{O}_{15}$ Aurivillius ceramic, Process. Appl. Ceram. 8, 145 (2014).

${ }^{35}$ S. R. Gawalia, K. G. Rewatkar and V. M. Nanoti, Structural and electrical properties of M-type nanocrystalline aluminium substituted calcium hexaferrites, Adv. Appl. Sci. Res. 3, 2672 (2012). 